\title{
Commonplace
}

\section{Toward Transformation: Scholarly Communications in Perilous Times}

Jennie Rose Halperin

Published on: Sep 29, 2020

DOI: $10.21428 / 6 \mathrm{ffd} 8432.44 \mathrm{a} 18 \mathrm{fce}$

License: Creative Commons Attribution 4.0 International License (CC-BY 4.0). 
In the face of "shrinking library budgets, overpriced journals, unpurchased monographs, and oligopolistic analytics platforms (not to mention demand for increased speed and access)", what does it mean for universities to take a more active role not only in the production but also in the dissemination of scholarship? While Brand provides a persuasive argument for why universities should actively engage with and transform knowledge infrastructure, the question remains how this change could take place, particularly in light of COVID austerity that will impact the university for years to come.

In most cases, the university under COVID presents a frightening new reality: lowered enrollment fears combined with the threat of lower returns on endowments and decreased public funding of the sciences (during a global health crisis, no less) creates a crisis exacerbated by insecurity and scarcity within the administrative class. Hiring and salary freezes, a culture of fear and caution, and shrinking budgets mean it may be a long time before institutions allocate appropriate resources to "incubate home-grown technologies and spark a movement toward greater institutional investment in knowledge infrastructure." The Knowledge Futures Group provides an interesting case study: started at MIT in 2018, the group became an independent nonprofit in 2020 to suit its innovative approach to platforming and product. In creating a functionally independent structure but still keeping a close relationship with the MIT Press, the KFG has been able to "manifest" the future of publishing while still maintaining its independence and agility. University-as-incubator is a persuasive model, and in many ways a model of what investment in knowledge infrastructure could be.

Perhaps the research university's reluctance to let projects fly can begin to answer the question regarding university underinvestment in knowledge infrastructure, with pay-to-publish as the norm, when this system is so clearly bad for universities and researchers. Extreme consolidation, outrageous publishing profit margins, and theft of research outcomes is the current status quo, and only a significant amount of investment in infrastructure by forward thinking players in the field will even remotely shift the paradigm. In the face of these challenges, made more distinct by the rapid spread of disinformation, universities continue to pay out to big publishers rather than invest in the projects that could actually transform the landscape and form collaborative, creative futures.

I agree with Brand that the university has an imperative to direct resources toward the "flow of research communications" not limited to data, software, and open repositories and also to not devalue the skill of publishing professionals, but in many cases, MIT Press as exception, the publisher and the University are at odds. The current crisis did not spring from research institutions working in community with publishers in a consensus or collaborative model. The data brokering, pricey publishing models, and rampant consolidation of the industry arose out of a drive for profit that has its roots in treating public research like a private resource to be bought and sold back to institutions. 
If research universities truly want to continue to be the "locus of empirical research and critical inquiry," the current moment could be treated as an opportunity rather than another excuse to lock down people, resources, and knowledge through performative administrative austerity. Moving away from "big deals" can provide an impetus to invest in infrastructure and people rather than vendor capitalists. With many people searching for work and meaning during the current economic and social crisis, university libraries and presses could work in collaboration to build and support infrastructure with an emphasis on transformative change. This may mean supporting extant projects, forming new alliances, or collaborating with known partners to seriously reconsider the current landscape.

This mission can and should be situated in the university, but it will only happen if the university provides the appropriate resources. Redefining their role as liberating rather than stifling, fostering new kinds of work for innovators in the field, launching new initiatives, and "manifesting" the world as it could be, scholarly communications could be more crucial than ever. It's up to university administrations, libraries, and scientists to decide if they are willing to say no to the scarcity model and move toward a model of abundance, respect, and community-minded research inputs and outcomes. 